\title{
Transparent Assessment of the Supervision Information in China's Food Safety: A Fuzzy-ANP Comprehensive Evaluation Method
}

\author{
Tingqiang Chen, Lei Wang, and Jining Wang \\ School of Economics and Management, Nanjing University of Technology, Nanjing 211816, China \\ Correspondence should be addressed to Jining Wang; wangjn163@126.com
}

Received 26 November 2016; Accepted 19 February 2017; Published 20 March 2017

Academic Editor: Egidio De Benedetto

Copyright (C) 2017 Tingqiang Chen et al. This is an open access article distributed under the Creative Commons Attribution License, which permits unrestricted use, distribution, and reproduction in any medium, provided the original work is properly cited.

\begin{abstract}
Improving transparency of food safety supervision information can reduce the occurrence of information asymmetry, decrease food safety incidents, and promote socially joint regulation for food safety. In this study, an index system of food safety supervision information transparency (FSSIT) is constructed using the fuzzy-ANP comprehensive evaluation model. Using this system, the FSSIT in China is evaluated. A total of 1651 questionnaires containing 139525 data are collected from food and drug administration (FDA), consumer association (CA), and media at the central, provincial, prefectural, and county levels. Empirical results indicate that the FSSIT achieves a qualified level; however, the works of FDA, CA, and media still present deficiencies. The information transparency in the entirety presents deficiencies and gradually declines when that in the administrative level decreases. The economic development level indirectly determines the transparency level, and the transparency level does not conform to China's current economic development level.
\end{abstract}

\section{Introduction}

The State Council of the People's Republic of China issued arrangements on food safety work in 2016, and these provisions put emphasis on improving the information disclosure mechanism, promoting the construction of major information technology projects, and accelerating socially joint regulation for food safety. These arrangements highlight China's attention to food safety and its information transparency.

Information of food safety supervision directly affects the public trust in all kinds of food safety information $[1,2]$. In the degree of food safety supervision information transparency (FSSIT), information transparency mainly refers to the fact that stakeholders have convenient access to the information $[3,4]$, while food safety means food causes no harm to human health $[5,6]$. From the perspective of a consumer, transparency of food safety information is the way to achieve its supervision [7]. An important task in supervising transparency of food safety information is the realization of FSSIT [8]. The behavior of food companies can be improved and the possibility of the supervision department dereliction can be reduced through the collective reputation mechanism [9-12].

The gradual development of research on food safety supervision has shown that the information asymmetry of food safety supervision cannot be effectively reduced only by supervision of the government and self-discipline of food companies [13]. An effective solution is to construct a mode of socially joint regulation for food safety such that all food safety supervision subjects can effectively and rationally participate in the governance of food safety $[2,14,15]$.

At present, the domestic and international research on FSSIT is very rare. A latest research builds China's index system of food safety supervision transparency to evaluate its level in China's food safety supervision departments $[16,17]$. However, the evaluation subjects are supervision departments not social supervision subjects. Moreover, the investigation content does not contain food safety supervision at the county level. Meeting the country's requirements of building a highly efficient and socially joint management system is difficult. Therefore, a comprehensive and systematic study on FSSIT in China is still lacking. 
In light of the above considerations, the index system of FSSIT is established in this study using the fuzzy-ANP comprehensive evaluation model and on the basis of the laws and regulations of China's food safety supervision and existing literature analysis. A total of 1651 questionnaires containing 139525 data are collected from food and drug administration (FDA), consumer association (CA), and media (in this paper, food and drug administration (FDA) refers to the government departments responsible for the supervision of food and drug administration, consumer association (CA) refers to the organizations that protect the interests of consumers, and media refers to newspapers, news websites, and the We-media) at the central, provincial, prefectural, and county levels. On the basis of these data, the FSSIT level is evaluated. The rest of the paper is organized as follows. Section 2 presents the setup of the FSSIT index system. Section 3 introduces the fuzzy-ANP comprehensive evaluation model and analyzes its applicability. Section 4 discusses an empirical research based on 1651 questionnaires containing 139525 data from FDA, CA, and media at the central, provincial, prefectural, and county levels. Section 5 discusses and analyzes the results of the empirical study. Finally, Section 6 summarizes and elaborates the conclusions of the study.

\section{Construction of Evaluation Index System}

FDA, CA, and media are the food safety supervision subjects in China and are the main publishers of FSSIT in the country. The information released by these bodies has wide coverage and high degree of public recognition. Food safety is the most basic livelihood project, but the public's access right to food safety information depends mainly on FDA, CA, and media. In addition, other subjects of food safety supervision still present problems, such as independent supervision and unreasonable supervision system [18]. Therefore, consumer and other supervision subjects of food safety present a limited effect on FSSIT. On this basis, this study evaluates China's FSSIT from three dimensions only: government, CA, and media.

2.1. FSSIT of Government. The government plays a leading role in food safety supervision works such that low level of supervision information transparency negatively affects its reputation [12]. These adverse effects are mainly as follows. First, FDA cannot fully obtain comprehensive information from food companies and implement the supervision work owing to its own conditions [19-22]. Accordingly, food companies may utilize food safety supervision loopholes to harm the interests of consumers [23]. In this case, the supervisees capture supervisors, government supervision becomes disordered [24], and the reputation of FDA becomes damaged. Second, the supervision information of government is relatively nontransparent; thus, FDA easily experiences group trust crisis in case of food safety incident [25-27]. Therefore, the following four aspects can be considered in improving the FSSIT of government.
2.1.1. Food Safety Information Platform of Government. Openness is the basis of transparency. The government sets up an effective food safety information platform that can show the transparency of the supervision process. The platform ensures public's access right to food safety information [28, 29] improves the efficiency of public's access to information [12], and publicizes food safety knowledge [30]. According to the existing research results and the "Food Safety Law of the People's Republic of China" (food safety law hereinafter), the food safety information platform of government should be subdivided into 13 indexes to evaluate FSSIT; these indexes are overall situation of food safety information, guiding information of supervision information, supervision information directory, key supervision information, food safety standard information, food safety risk warning information, information on administrative punishment for food safety issues, qualification accreditation information of food inspection agencies, name list of food safety inspection agencies, name list of production and business licenses, certification information of company quality system, supervision organization structure and personnel information, and food safety credit file information [31-37].

2.1.2. Food Safety Accident Emergency Information of Government. The emergency handling capability of FDA on food safety accidents directly reflects its administrative efficiency [38]. Any serious problem in information transparency of food safety accident can result in vicious rumor of "herd instinct." Therefore, FDA should maintain a sufficient transparency of food safety accident emergency information to reduce the rumor. According to the existing research results and "food safety law," the food safety accident emergency information of government should be subdivided into six indexes to evaluate FSSIT; these indexes are food safety accident classification, accident disposal commanding system and responsibility information, prevention and warning mechanism information, disposal procedure information, emergency safeguarding measure information, and accident investigation and disposal information $[31,34,35,38]$.

\subsubsection{Food Safety Sampling Information of Government.} China's inspection system of food safety supervision has clearly stipulated that FDA must disclose the inspection results [35]. The sampling information of FDA is a dynamic quality testing content and is the most important information that FDA needs to disclose [31]. According to the existing research results and "food safety law," government food safety sampling information should be subdivided into three indexes to evaluate FSSIT; these indexes are sampling object information, sampling qualified information, and sampling unqualified information $[31,34,35]$.

2.1.4. Information for Safeguarding the Government Supervision Mechanism. FDA needs a clear, transparent mechanism to safeguard food safety supervision. This mechanism can promote the responsibility clarification and enhance public awareness on FDA and is an important step to improve the FSSIT of government. According to the existing research 
results and "food safety law," the information for safeguarding the government supervision mechanism should be subdivided into five indexes to evaluate FSSIT; these indexes are open management mechanism information of supervision information, annual report for disclosure supervision, report processing information, supervision responsibility mechanism information, and supervision evaluation mechanism information $[31,34,35,38,39]$.

2.2. FSSIT of CA. Problems in food safety and its supervision are characterized by sociality. However, the traditional model of "single food safety supervision" is monopolized by the government and excludes public supervision; thus, this model presents low supervision efficiency and poor supervision information transparency. According to the empirical study on the American food safety supervision, government supervision insignificantly reduces the outbreak of foodborne diseases [40]. Therefore, the construction of socially joint regulation mode for food safety [41] is an effective way to reduce the probability of food safety problems and improve the entire FSSIT [35]. CA is an important force in socially joint regulation for food safety. Accordingly, this study improves the FSSIT of CA mainly from the following three aspects.

2.2.1. Supervision Information of CA. Participation of CA in food safety supervision can reduce the information asymmetry of food safety and improve the efficiency of public participation [31]. Moreover, CA can use the social punishment effect to produce a deterrent against the illegal behavior of food companies [12]. According to the existing research results and "food safety law," the supervision information of CA should be subdivided into three indexes to evaluate FSSIT; these indexes are supervision mechanism information, supervision organization structure and personnel composition, and supervision evaluation information $[27,31,35$, $39,42]$.

2.2.2. Integrity Building Information of CA. The important works of CA are to conduct integrity building [43], regulate the behavior of food companies, and warn consumers through the "black name list system," credit rating, and other means. According to the existing research results and "food safety law," the integrity building information of CA should be subdivided into three indexes to evaluate FSSIT; these indexes are integrity building standard information, name list of accredited company brands, and name list of nonaccredited company brands [27, 31, 35, 39, 42, 43].

2.2.3. Information for Safeguarding the Supervision Mechanism of $C A$. Sound supervision mechanism must be developed to improve the supervision efficiency of CA. The social supervision function of CA can best embody the supervision role [38]. According to the existing research results and "food safety law," the information for safeguarding the supervision mechanism of CA should be subdivided into five indexes to evaluate FSSIT; these indexes are social supervision function information, annual report for disclosure supervision, management mechanism for disclosing supervision information, supervision responsibility mechanism, and perfect degree and operation situation of food safety information platform $[27,31,35,39,42]$.

2.3. FSSIT of Media. Media is also an important force in socially joint regulation for food safety. As one of the main publishers of food safety information, media plays an irreplaceable role in the food safety social supervision. Media involves in socially joint regulation to improve the supervision efficiency of food safety $[27,44]$ and protect the public's access right to food safety information. Therefore, this study improves the FSSIT of media mainly from the following two aspects.

2.3.1. Supervision Information of Media. Media plays a unique role in the exposure of food safety problems. During the "Sanlu milk powder" incident or the "Shuanghui clenbuterol" incident, media expanded the influence through the report in the early stage and then continued to place pressure on the government supervision work by tracking reports in the later stage [27]. According to the existing research results and "food safety law," the supervision information of media should be subdivided into four indexes to evaluate FSSIT; these indexes are food safety incident reports, food safety incident tracking reports, authenticity and impartiality of food safety report, and social supervision function information of media $[27,31,35,39,43]$.

2.3.2. Food Safety Publicity of Media. The promotion of laws, regulations, standards, and knowledge on food safety relies on media. However, the present performance of media in this area is relatively weak and needs to be strengthened. According to the existing research results and "food safety law," food safety publicity of media should be subdivided into two indexes to evaluate FSSIT; these indexes are publicity of food safety laws and regulations and publicity of food safety standards and knowledge [27, 31, 35, 39, 43].

By combining the experts' opinion (the Delphi expert group consists of 15 experts, including 6 food safety management professors from colleges and universities, 3 FDA experts, 2 food safety media experts, 2 CA experts, and 2 food business experts) using the Delphi method, the index system of FSSIT is constructed and is shown in Table 1.

\section{Evaluation Model}

The fuzzy-ANP comprehensive evaluation model is composed of the analytic network process (ANP) and the fuzzy comprehensive evaluation method. The ANP compensates the defects of the analytic hierarchy process [45], and the fuzzy comprehensive evaluation method based on the membership theory of fuzzy mathematics effectively evaluates qualitative indexes [46]. Therefore, the fuzzy-ANP comprehensive evaluation model presents many advantages in evaluation and analysis. In the process of food safety supervision, the same food safety supervision subjects exhibit 
TABLE 1: Index system of FSSIT.

\begin{tabular}{|c|c|c|c|}
\hline Objective & First-level index & Second-level index & Third-level index \\
\hline \multirow{13}{*}{ FSSIT (A) } & \multirow{13}{*}{$\begin{array}{l}\text { FSSIT of government } \\
\qquad\left(\mathrm{B}_{1}\right)\end{array}$} & \multirow{13}{*}{$\begin{array}{l}\text { Information platform of } \\
\text { food safety of } \\
\text { government }\left(C_{1}\right)\end{array}$} & Overall situation of food safety information $\left(\mathrm{C}_{11}\right)$ \\
\hline & & & Guiding information for supervision information $\left(C_{12}\right)$ \\
\hline & & & Supervision information disclosing directory $\left(\mathrm{C}_{13}\right)$ \\
\hline & & & Key information of supervision $\left(\mathrm{C}_{14}\right)$ \\
\hline & & & Standard information of food safety $\left(\mathrm{C}_{15}\right)$ \\
\hline & & & Warning information of food safety risk $\left(\mathrm{C}_{16}\right)$ \\
\hline & & & $\begin{array}{l}\text { Information on administrative punishment of food safety issue } \\
\qquad\left(\mathrm{C}_{17}\right)\end{array}$ \\
\hline & & & $\begin{array}{l}\text { Qualification accreditation information of food inspection } \\
\text { agency }\left(\mathrm{C}_{18}\right)\end{array}$ \\
\hline & & & Name list of food safety inspection agencies $\left(\mathrm{C}_{19}\right)$ \\
\hline & & & Name list of production and business licenses $\left(\mathrm{C}_{110}\right)$ \\
\hline & & & Certification information of company quality system $\left(\mathrm{C}_{111}\right)$ \\
\hline & & & $\begin{array}{l}\text { Supervision organization structure and personnel composition } \\
\text { information }\left(C_{112}\right)\end{array}$ \\
\hline & & & Food safety credit file information $\left(\mathrm{C}_{113}\right)$ \\
\hline \multirow{6}{*}{ FSSIT (A) } & \multirow{6}{*}{$\begin{array}{l}\text { FSSIT of government } \\
\qquad\left(\mathrm{B}_{1}\right)\end{array}$} & \multirow{6}{*}{$\begin{array}{l}\text { Food safety accident } \\
\text { emergency information } \\
\text { of government }\left(\mathrm{C}_{2}\right)\end{array}$} & Food safety accident classification information $\left(\mathrm{C}_{21}\right)$ \\
\hline & & & $\begin{array}{c}\text { Accident disposal organization and commanding system and } \\
\text { responsibility information }\left(\mathrm{C}_{22}\right)\end{array}$ \\
\hline & & & Prevention and warning mechanism information $\left(\mathrm{C}_{23}\right)$ \\
\hline & & & Disposal procedure information $\left(\mathrm{C}_{24}\right)$ \\
\hline & & & Emergency and safeguarding information $\left(\mathrm{C}_{25}\right)$ \\
\hline & & & Accident investigation and disposal information $\left(\mathrm{C}_{26}\right)$ \\
\hline \multirow{3}{*}{ FSSIT (A) } & \multirow{3}{*}{$\begin{array}{l}\text { FSSIT of government } \\
\qquad\left(\mathrm{B}_{1}\right)\end{array}$} & \multirow{3}{*}{$\begin{array}{l}\text { Food safety sampling } \\
\text { information of } \\
\text { government }\left(\mathrm{C}_{3}\right)\end{array}$} & Sampling object information $\left(\mathrm{C}_{31}\right)$ \\
\hline & & & Sampling qualified information $\left(\mathrm{C}_{32}\right)$ \\
\hline & & & Sampling unqualified information $\left(\mathrm{C}_{33}\right)$ \\
\hline \multirow{6}{*}{ FSSIT (A) } & \multirow{6}{*}{$\begin{array}{l}\text { FSSIT of government } \\
\qquad\left(\mathrm{B}_{1}\right)\end{array}$} & \multirow{6}{*}{$\begin{array}{l}\text { Information for } \\
\text { safeguarding the } \\
\text { government supervision } \\
\text { mechanism }\left(\mathrm{C}_{4}\right)\end{array}$} & Open management information of supervision information \\
\hline & & & $\left(\mathrm{C}_{41}\right)$ \\
\hline & & & Annual report for supervision information $\left(\mathrm{C}_{42}\right)$ \\
\hline & & & Report processing information $\left(\mathrm{C}_{43}\right)$ \\
\hline & & & Supervision responsibility mechanism information $\left(\mathrm{C}_{44}\right)$ \\
\hline & & & Supervision evaluation mechanism information $\left(\mathrm{C}_{45}\right)$ \\
\hline \multirow{3}{*}{ FSSIT (A) } & \multirow{3}{*}{ FSSIT of CA $\left(B_{2}\right)$} & \multirow{3}{*}{$\begin{array}{l}\text { Supervision information } \\
\quad \text { of } \mathrm{CA}\left(\mathrm{C}_{5}\right)\end{array}$} & Supervision mechanism information $\left(\mathrm{C}_{51}\right)$ \\
\hline & & & $\begin{array}{l}\text { Supervision organization structure and personnel composition } \\
\text { information }\left(\mathrm{C}_{52}\right)\end{array}$ \\
\hline & & & Supervision evaluation information $\left(\mathrm{C}_{53}\right)$ \\
\hline \multirow{3}{*}{ FSSIT (A) } & \multirow{3}{*}{ FSSIT of CA $\left(B_{2}\right)$} & \multirow{3}{*}{$\begin{array}{l}\text { Integrity building } \\
\text { information of } \mathrm{CA}\left(\mathrm{C}_{6}\right)\end{array}$} & Integrity building standard information $\left(\mathrm{C}_{61}\right)$ \\
\hline & & & Name list of accredited company brands $\left(\mathrm{C}_{62}\right)$ \\
\hline & & & Name list of non-accredited company brands $\left(\mathrm{C}_{63}\right)$ \\
\hline \multirow{4}{*}{ FSSIT (A) } & \multirow{4}{*}{ FSSIT of CA $\left(B_{2}\right)$} & \multirow{4}{*}{$\begin{array}{l}\text { Information for } \\
\text { safeguarding the } \\
\text { supervision mechanism } \\
\text { of CA }\left(C_{7}\right)\end{array}$} & Information of social supervision function $\left(\mathrm{C}_{71}\right)$ \\
\hline & & & $\begin{array}{l}\text { Disclosure annual report of the supervision information }\left(\mathrm{C}_{72}\right) \\
\text { Disclosure management mechanism information of supervision } \\
\text { information }\left(\mathrm{C}_{73}\right)\end{array}$ \\
\hline & & & Supervision responsibility mechanism information $\left(\mathrm{C}_{74}\right)$ \\
\hline & & & $\begin{array}{l}\text { Perfect degree and operation situation of food safety } \\
\text { information platform }\left(\mathrm{C}_{75}\right)\end{array}$ \\
\hline \multirow{4}{*}{ FSSIT (A) } & \multirow{4}{*}{ FSSIT of media $\left(\mathrm{B}_{3}\right)$} & \multirow{4}{*}{$\begin{array}{l}\text { Supervision information } \\
\text { of media }\left(\mathrm{C}_{8}\right)\end{array}$} & Food safety incident report $\left(\mathrm{C}_{81}\right)$ \\
\hline & & & Food safety incident tracking report $\left(\mathrm{C}_{82}\right)$ \\
\hline & & & Authenticity and impartiality of food safety report $\left(\mathrm{C}_{83}\right)$ \\
\hline & & & Social supervision function information of media $\left(\mathrm{C}_{84}\right)$ \\
\hline \multirow{2}{*}{ FSSIT (A) } & FSSIT of media $\left(\mathrm{B}_{2}\right)$ & Publicity for food safety & Publicity of food safety laws and regulations $\left(\mathrm{C}_{91}\right)$ \\
\hline & FSsH or media $\left(B_{3}\right)$ & of media $\left(\mathrm{C}_{9}\right)$ & Publicity of food safety standards and knowledge $\left(\mathrm{C}_{92}\right)$ \\
\hline
\end{tabular}




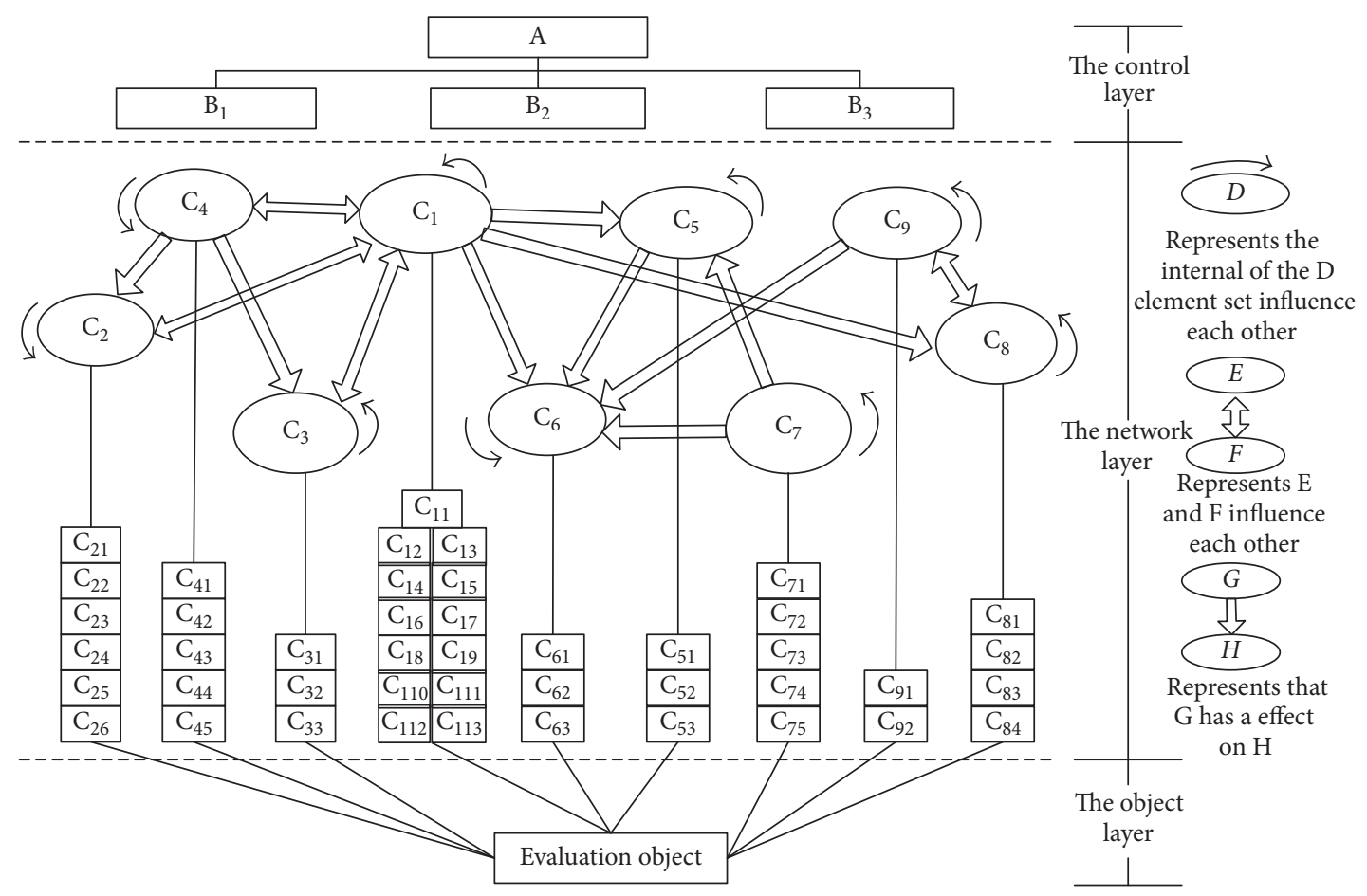

FIgURE 1: Network structure of ANP of FSSIT.

a clear hierarchy. In other words, the various types of food safety supervision subjects show a significant dependency relationship. Thus, the influencing factors of FSSIT possess a typical level and dependent relationship. Accordingly, the index system of FSSIT forms an organic whole with a hierarchical network structure. A few indexes of FSSIT cannot be directly quantified because they present intervals and fuzzy characteristics on the value. Thus, evaluating FSSIT using the fuzzy-ANP comprehensive evaluation model is highly scientific and applicable.

3.1. Constructing the Network Structure of ANP. In the network structure of FSSIT, the control layer contains the target and criteria; the target is $\mathrm{A}$, and the criteria are the first-level indexes of the index system including $B_{1}, B_{2}$, and $B_{3}$. The network layer includes nine sets of elements that correspond to second- and third-level indexes of the index system; these sets are $\mathrm{C}_{1}, \mathrm{C}_{2}, \mathrm{C}_{3}, \mathrm{C}_{4}, \mathrm{C}_{5}, \mathrm{C}_{6}, \mathrm{C}_{7}, \mathrm{C}_{8}$, and $\mathrm{C}_{9}$. According to the mutual influence relationship within the evaluation index set of elements and between the set of elements and the indexes, the network structure of ANP is constructed and is shown in Figure 1.

3.2. Determination of the Index Weight. With the help of ANP and Delphi expert scoring, the weight of each FSSIT indexes is determined. The specific process is as follows.

Step 1. Build a super matrix. Assume that ANP control layer criterion contains $B_{s}(s=1,2, \ldots, m)$, the network layer
TABLE 2: Scale method of 1-9 in comparison.

\begin{tabular}{|c|c|}
\hline Scale & Definition \\
\hline 1 & $\begin{array}{l}\text { Element } i \text { and element } j \text { present the } \\
\text { same importance }\end{array}$ \\
\hline 3 & $\begin{array}{l}\text { Element } i \text { is moderately more } \\
\text { important than element } j\end{array}$ \\
\hline 5 & $\begin{array}{c}\text { Element } i \text { is strongly more important } \\
\text { than element } j\end{array}$ \\
\hline 7 & $\begin{array}{l}\text { Element } i \text { is very strongly more } \\
\text { important than element } j\end{array}$ \\
\hline 9 & $\begin{array}{c}\text { Element } i \text { is extremely more important } \\
\text { than element } j\end{array}$ \\
\hline $2,4,6,8$ & $\begin{array}{l}\text { Median values of the two adjacent } \\
\text { judgments }\end{array}$ \\
\hline Reciprocal & $\begin{array}{l}\text { The importance scale of element } j \text { to } \\
\text { element } i\end{array}$ \\
\hline
\end{tabular}

contains a set of elements $C_{N}(N=1, \ldots, n)$, and $C_{i}$ contains elements $C_{i 1}, C_{i 2}, \ldots, C_{i n}, i=1,2, \ldots, N$. According to the criterion of the control layer element $B_{s}$, use element $C_{j 1}$ of $C_{j}$ as the subcriterion, construct the judgment matrix based on the scale method of 1-9 as shown in Table 2, and obtain the normalized feature vector $\left(w_{i 1}, w_{i 2}, \ldots, w_{i n}\right)^{T}$. Then, test the consistency of the obtained vector; the test passes when CR is less than 0.1; otherwise, the value of the matrix element needs to be adjusted. Similarly, obtain the normalized feature vector 
of other elements, and then obtain a super matrix, denoted as $W_{i j}$.

$$
W_{i j}=\left[\begin{array}{cccc}
w_{i 1}{ }^{(j 1)} & w_{i 2}{ }^{(j 2)} & \cdots & w_{i 1}{ }^{\left(j n_{j}\right)} \\
w_{i 2}{ }^{(j 1)} & w_{i 2}{ }^{(j 2)} & \cdots & w_{i 2}{ }^{\left(j n_{j}\right)} \\
\vdots & \vdots & \ddots & \vdots \\
w_{i n_{i}}{ }^{(j 1)} & w_{i n_{i}}{ }^{(j 2)} & \cdots & w_{i n_{i}}{ }^{\left(j n_{j}\right)}
\end{array}\right] .
$$

The column vector of $W_{i j}$ in this study is the element $C_{i 1}, C_{i 2}, \ldots, C_{i n}$ in $C_{i}$. If the element in $C_{j}$ is unaffected by the element in $C_{i}$, then $W_{i j}=0$. In the same way, the super matrix of other control elements can be obtained. Therefore, the super matrix $W$ under the criterion $B_{s}$ is obtained as follows:

$$
W=\left[\begin{array}{cccc}
w_{11} & w_{12} & \cdots & w_{1 N} \\
w_{21} & w_{22} & \cdots & w_{2 N} \\
\vdots & \vdots & \ddots & \vdots \\
w_{N 1} & w_{N 2} & \cdots & w_{N N}
\end{array}\right]
$$

Step 2. Construct the weighted matrix and weighted super matrix. Under the criterion $B_{s}$, the importance of the relative criterion of element $C_{j}(j=1,2, \ldots, N)$ is compared to obtain a normalized row sequence vector $\left(a_{1 j}, a_{2 j}, \ldots, a_{N j}\right)$ such that a weighted matrix is obtained as follows:

$$
\begin{aligned}
A=\left[\begin{array}{cccc}
a_{11} & a_{12} & \cdots & a_{1 N} \\
a_{21} & a_{22} & \cdots & a_{2 N} \\
\vdots & \vdots & \ddots & \vdots \\
a_{N 1} & a_{N 2} & \cdots & a_{N N}
\end{array}\right] & \left(a_{i j} \in[0,1], \sum^{N} a_{i j}=1\right)
\end{aligned}
$$

Therefore, the weighted super matrix is constructed as follows:

$$
\begin{aligned}
\bar{W}=\overline{W_{i j}}=A \times W= & \left(a_{i j} \times W_{i j}\right) \\
& (i=1,2, \ldots, N, j=1,2, \ldots, N) .
\end{aligned}
$$

On the basis of the results of the super matrix and weighted super matrix, the local weight and overall weight of FSSIT indexes can be obtained. The weights used in this study are local weights.

3.3. Determination of Evaluation Rating and Rules. The evaluation rating is assumed as follows: $v=\left(v_{1}, v_{2}, \ldots, v_{N}\right)(N=$ $1,2, \ldots$, number of ranks). The evaluation rating is divided into five grades: good, relatively good, general, relatively poor, and poor; the values of these grades are $100,75,50,25$, and 0.
3.4. Determination of Fuzzy Relation Matrix. The fuzzy relation matrix is defined as follows:

$$
R=\left(r_{i j}\right)_{N \times M}=\left[\begin{array}{cccc}
r_{11} & r_{12} & \cdots & r_{1 M} \\
r_{21} & r_{22} & \cdots & r_{2 M} \\
\vdots & \vdots & \ddots & \vdots \\
r_{N 1} & r_{N 2} & \cdots & r_{N M}
\end{array}\right]
$$

Among them, $R$ is a member of the index number $i$ of the level number $j$ and $r_{i j}=$ the number of the indicator number $i$ to select the level $v_{i}$ /the number of participating evaluation.

3.5. Determination of the Comprehensive Evaluation Level. A comprehensive evaluation vector is established by the fuzzy comprehensive operation of the weight set and the fuzzy relation matrix.

$$
\begin{aligned}
S_{i} & =W_{i} \times R \\
& =\left(w_{i 1}, w_{i 2}, \ldots, w_{i N}\right)\left[\begin{array}{cccc}
r_{11} & r_{12} & \cdots & r_{1 M} \\
r_{21} & r_{22} & \cdots & r_{2 M} \\
\vdots & \vdots & \ddots & \vdots \\
r_{N 1} & r_{N 2} & \cdots & r_{N M}
\end{array}\right] \\
& =\left(s_{1}, s_{2}, \ldots, s_{M}\right) .
\end{aligned}
$$

In the comprehensive evaluation vector of FSSIT, $M$ is equal to 5 . Therefore, the final FSSIT score obtained by the weighted average method is $T=100 \times s_{1}+75 \times s_{2}+50 \times s_{3}+$ $25 \times s_{4}+0 \times s_{5}$.

\section{Empirical Research}

4.1. Questionnaire Design. The aims of this study are as follows: evaluate the level of the entire FSSIT, various types of food safety supervision subjects, and different administrative levels and regions in China; explore the existing problems; boost the improvement in food safety management; promote the public's access right to food safety information. On the basis of the FSSIT index system, the questionnaire for FDA, $\mathrm{CA}$, and media is designed. The five-grade classification method is used to score each item in the questionnaire (each item is assigned a corresponding level of five scoring criteria to ensure the objectivity of scoring.); "good" means 100 points, "relatively good" means 75 points, "general" means 50 points, "relatively poor" means 25 points, and "poor" means 0 point (the final FSSIT score rating criteria are as follows: 100 points mean a full mark, 60 points and above are qualified, the score within $[0,30]$ is poor, the score within $[30,60]$ is relatively poor, the score within $[60,75]$ is general, the score within $[75,90]$ is relatively good, and the score within $[90,100]$ is well.). We conduct a presurvey to carry out the survey. 
TABLE 3: Test of reliability and validity.

\begin{tabular}{|c|c|c|c|c|c|}
\hline Subject of investigation & Cronbach's alpha & $\mathrm{KMO}$ & Bartlett & $\mathrm{df}$ & sig \\
\hline FDA & 0.986 & 0.974 & 31487.675 & 351 & 0.000 \\
\hline $\mathrm{CA}$ & 0.983 & 0.943 & 13869.744 & 55 & 0.000 \\
\hline media & 0.971 & 0.899 & 2311.163 & 15 & 0.000 \\
\hline
\end{tabular}

TABLE 4: Characteristics of different administrative levels.

\begin{tabular}{lcccccc}
\hline \multirow{2}{*}{ Administrative level } & \multicolumn{2}{c}{ FDA } & \multicolumn{2}{c}{ CA } & \multicolumn{2}{c}{ Entirety } \\
& Frequency & Proportion & Frequency & Proportion & Frequency & Proportion \\
\hline Center & 1 & 0.001 & 1 & 0.001 & 0.001 \\
Province & 31 & 0.045 & 31 & 0.045 & 62 & 0.045 \\
Prefecture & 333 & 0.480 & 330 & 0.482 & 663 & 0.481 \\
County & 329 & 0.474 & 323 & 0.472 & 652 & 1379 \\
Sum & 694 & 1 & 685 & 1 & 1 \\
\hline
\end{tabular}

4.2. Sample. FDA is the government department that is responsible for food safety supervision, according to the 15 th provision of Regulations of the People's Republic of China on the Disclosure of Government Information. FDA should initiate in disclosing food safety supervision information, and this information should be accessible to the public. CA can reasonably support the supervision works of government for food safety and reduce the information asymmetry of food safety. Media can use its capability to improve the dissemination of food safety supervision information, deter food companies through the social effect of punishment, and rectify the behavior of food safety supervision department in government with the help of the collective reputation. Therefore, FDA, CA, and media are used as investigation objects in evaluating China's FSSIT.

The survey started from June 2016 to October 2016 and focuses mainly on FDA, CA, and media at the central, provincial, prefectural, and county levels. To ensure the objectivity of the survey results, the survey data were obtained from the official websites of FDA, CA, and media or by the assistance of a telephone survey. The data were collected by the end of September 2016. In this survey, a questionnaire represents a food safety supervision subject. A total of 697 completed questionnaires were obtained from FDA; 3 were invalid and 694 were valid among these questionnaires, and the effective rate was $99.570 \%$. A total of 697 questionnaires were obtained from CA; 12 were invalid and 685 were valid among these questionnaires, and the effective rate was $98.278 \%$. A total of 300 questionnaires were obtained from media; 28 were invalid and 272 were valid among these questionnaires, and the effective rate was $90.667 \%$. Therefore, 1694 questionnaires were completed; 43 were invalid and 1651 were valid among these questionnaires, and the effective rate was $97.462 \%$. Finally, we obtained 139525 valid survey data.

4.3. Data Analysis. In this study, the SPSS software is used to test the reliability and validity of the survey results, as shown in Table 3.
Table 3 shows that the Cronbach's alpha values of FDA, CA, and media are $0.986,0.983$, and 0.971 , all of which are above 0.9 . Therefore, the measure of FDA, CA, and media presents good internal consistency and stability, and the reliability is quite good. The KMO values of FDA and CA are above 0.9 , indicating that the factor analysis is quite good and the validity is quite high. The KMO value of media is above 0.8 , indicating that the factor analysis is good and the validity is high.

The characteristics of different administrative levels, geographical regions, and economic regions of FDA, CA, and media are shown in Tables 4-6. (For the convenience of statistics and analysis, the central is compared in statistics; therefore, the central and provincial results appear side by side. At the central level, we only investigate China's Food and Drug Administration (CFDA), China's Consumers Association, and national media, such as People's Daily.)

The survey involves FDA, CA, and media at the central, provincial, prefectural, and county levels. However, when investigating municipalities directly under the central government, we only investigate FDA and CA. No specific subdivision is applied to prefecture and county. The media survey mainly involves the mainstream media and We-media at the central and provincial levels.

\subsection{Evaluation and Analysis}

4.4.1. Weight Calculation. On the basis of the above weight calculation method and the help of the Super decision software, the weight of the indexes is obtained and is shown in Table 7.

4.4.2. Fuzzy Comprehensive Calculation. On the basis of 1651 questionnaires containing 139525 data from FDA, CA, and media and using the fuzzy-ANP comprehensive evaluation model, the transparency scores of various types of food safety supervision subjects are obtained. The scores in different 
TABLE 5: Characteristics of different geographical regions.

\begin{tabular}{|c|c|c|c|c|c|c|c|c|c|}
\hline \multirow{2}{*}{ Geographical regions } & \multirow{2}{*}{ Province } & \multicolumn{2}{|c|}{ FDA } & \multicolumn{2}{|c|}{$\mathrm{CA}$} & \multicolumn{2}{|c|}{ Media } & \multicolumn{2}{|c|}{ Entirety } \\
\hline & & Frequency & Proportion & Frequency & Proportion & Frequency & Proportion & Frequency & Proportion \\
\hline \multirow{7}{*}{ East China } & Shanghai & 1 & 0.001 & 1 & 0.001 & 6 & 0.022 & 8 & 0.005 \\
\hline & Jiangsu & 35 & 0.050 & 35 & 0.051 & 12 & 0.044 & 82 & 0.050 \\
\hline & Zhejiang & 32 & 0.046 & 32 & 0.047 & 15 & 0.055 & 79 & 0.048 \\
\hline & Anhui & 23 & 0.033 & 23 & 0.034 & 8 & 0.029 & 54 & 0.033 \\
\hline & Jiangxi & 22 & 0.032 & 18 & 0.026 & 4 & 0.015 & 44 & 0.027 \\
\hline & Shandong & 46 & 0.066 & 46 & 0.067 & 17 & 0.063 & 109 & 0.066 \\
\hline & Fujian & 23 & 0.033 & 23 & 0.034 & 10 & 0.037 & 56 & 0.034 \\
\hline \multicolumn{2}{|l|}{ Total } & 182 & 0.261 & 178 & 0.260 & 72 & 0.265 & 432 & 0.263 \\
\hline \multirow{5}{*}{ North China } & Beijing & 1 & 0.001 & 1 & 0.001 & 10 & 0.037 & 12 & 0.007 \\
\hline & Tianjin & 1 & 0.001 & 1 & 0.001 & 7 & 0.026 & 9 & 0.005 \\
\hline & Shanxi & 23 & 0.033 & 22 & 0.032 & 6 & 0.022 & 51 & 0.031 \\
\hline & Hebei & 32 & 0.046 & 31 & 0.045 & 7 & 0.026 & 70 & 0.042 \\
\hline & Neimenggu & 20 & 0.029 & 20 & 0.029 & 6 & 0.022 & 46 & 0.028 \\
\hline \multicolumn{2}{|c|}{ Total } & 77 & 0.110 & 75 & 0.108 & 36 & 0.133 & 188 & 0.113 \\
\hline \multirow{3}{*}{ Central China } & Henan & 40 & 0.058 & 39 & 0.057 & 10 & 0.037 & 89 & 0.054 \\
\hline & Hubei & 34 & 0.049 & 35 & 0.051 & 6 & 0.022 & 75 & 0.045 \\
\hline & Hunan & 31 & 0.045 & 31 & 0.045 & 9 & 0.033 & 71 & 0.043 \\
\hline \multicolumn{2}{|l|}{ Total } & 105 & 0.152 & 105 & 0.153 & 25 & 0.092 & 235 & 0.142 \\
\hline \multirow{3}{*}{ South China } & Guangdong & 41 & 0.059 & 41 & 0.060 & 18 & 0.066 & 100 & 0.061 \\
\hline & Guangxi & 23 & 0.033 & 23 & 0.034 & 8 & 0.029 & 54 & 0.033 \\
\hline & Hainan & 10 & 0.014 & 10 & 0.015 & 2 & 0.007 & 22 & 0.013 \\
\hline \multicolumn{2}{|l|}{ Total } & 74 & 0.106 & 74 & 0.109 & 28 & 0.102 & 176 & 0.107 \\
\hline \multirow{5}{*}{ Southwest China } & Sichuan & 35 & 0.050 & 35 & 0.051 & 10 & 0.037 & 80 & 0.048 \\
\hline & Guizhou & 13 & 0.019 & 13 & 0.019 & 2 & 0.007 & 28 & 0.017 \\
\hline & Yunnan & 20 & 0.029 & 17 & 0.025 & 7 & 0.026 & 44 & 0.027 \\
\hline & Chongqing & 1 & 0.001 & 1 & 0.001 & 5 & 0.018 & 7 & 0.004 \\
\hline & Xizang & 8 & 0.012 & 8 & 0.012 & 3 & 0.011 & 19 & 0.012 \\
\hline \multicolumn{2}{|l|}{ Total } & 77 & 0.111 & 74 & 0.108 & 27 & 0.099 & 178 & 0.108 \\
\hline \multirow{5}{*}{ Northwest China } & Shanxi & 14 & 0.020 & 14 & 0.020 & 8 & 0.029 & 36 & 0.022 \\
\hline & Gansu & 17 & 0.024 & 17 & 0.025 & 8 & 0.029 & 42 & 0.025 \\
\hline & Qinghai & 12 & 0.017 & 12 & 0.018 & 3 & 0.011 & 27 & 0.016 \\
\hline & Ningxia & 8 & 0.012 & 8 & 0.012 & 8 & 0.029 & 24 & 0.015 \\
\hline & Xinjiang & 40 & 0.058 & 40 & 0.058 & 7 & 0.026 & 87 & 0.053 \\
\hline \multicolumn{2}{|l|}{ Total } & 91 & 0.131 & 91 & 0.133 & 34 & 0.124 & 216 & 0.131 \\
\hline \multirow{3}{*}{ Northeast China } & Heilongjiang & 32 & 0.046 & 32 & 0.047 & 10 & 0.037 & 74 & 0.045 \\
\hline & Jilin & 24 & 0.035 & 24 & 0.035 & 5 & 0.018 & 53 & 0.032 \\
\hline & Liaoning & 31 & 0.045 & 31 & 0.045 & 11 & 0.040 & 73 & 0.044 \\
\hline Total & & 87 & 0.126 & 87 & 0.127 & 26 & 0.095 & 200 & 0.121 \\
\hline Center & & 1 & 0.001 & 1 & 0.001 & 24 & 0.088 & 26 & 0.016 \\
\hline Sum & & 694 & 1.000 & 685 & 1.000 & 272 & 1.000 & 1651 & 1.000 \\
\hline
\end{tabular}

administrative levels, geographical regions, and economic regions in China are shown in Tables 8-11.

As shown in Table 8, analyzing various types of food safety supervision subjects reveals that the FSSIT of media obtains the highest score and at a general level. The FSSIT of FDA and CA obtains a lower score but at a qualified level. The scores of the various types of food safety supervision subjects show that the FSSIT work in FDA, CA, and media presents a certain degree of loss. In addition, the overall score of FSSIT shows that China's entire FSSIT reaches an acceptable level at present. In other words, China has exerted much effort to improve FSSIT, but a certain extent of work loss still exists. Therefore, each type of of food safety supervision subjects needs to improve the FSSIT work. 
TABLE 6: Characteristics of different economic regions.

\begin{tabular}{|c|c|c|c|c|c|c|c|c|c|}
\hline \multirow{2}{*}{ Economic regions } & \multirow{2}{*}{ Province } & \multicolumn{2}{|c|}{ FDA } & \multicolumn{2}{|c|}{$\mathrm{CA}$} & \multicolumn{2}{|c|}{ Media } & \multicolumn{2}{|c|}{ Entirety } \\
\hline & & Frequency & Proportion & Frequency & Proportion & Frequency & Proportion & Frequency & Proportion \\
\hline \multirow{10}{*}{ East part } & Beijing & 1 & 0.001 & 1 & 0.001 & 10 & 0.037 & 12 & 0.007 \\
\hline & Tianjin & 1 & 0.001 & 1 & 0.001 & 7 & 0.026 & 9 & 0.005 \\
\hline & Hebei & 32 & 0.046 & 31 & 0.045 & 7 & 0.026 & 70 & 0.042 \\
\hline & Shanghai & 1 & 0.001 & 1 & 0.001 & 6 & 0.022 & 8 & 0.005 \\
\hline & Jiangsu & 35 & 0.050 & 35 & 0.051 & 12 & 0.044 & 82 & 0.050 \\
\hline & Zhejiang & 32 & 0.046 & 32 & 0.047 & 15 & 0.055 & 79 & 0.048 \\
\hline & Fujian & 23 & 0.033 & 23 & 0.034 & 10 & 0.037 & 56 & 0.034 \\
\hline & Shandong & 46 & 0.066 & 46 & 0.067 & 17 & 0.063 & 109 & 0.066 \\
\hline & Guangdong & 41 & 0.059 & 41 & 0.060 & 18 & 0.066 & 100 & 0.061 \\
\hline & Hainan & 10 & 0.014 & 10 & 0.015 & 2 & 0.007 & 22 & 0.013 \\
\hline \multicolumn{2}{|l|}{ Total } & 222 & 0.317 & 221 & 0.322 & 104 & 0.383 & 547 & 0.331 \\
\hline \multirow{6}{*}{ Central } & Shanxi & 23 & 0.033 & 22 & 0.032 & 6 & 0.022 & 51 & 0.031 \\
\hline & Anhui & 23 & 0.033 & 23 & 0.034 & 8 & 0.029 & 54 & 0.033 \\
\hline & Jiangxi & 22 & 0.032 & 18 & 0.026 & 4 & 0.015 & 44 & 0.027 \\
\hline & Henan & 40 & 0.058 & 39 & 0.057 & 10 & 0.037 & 89 & 0.054 \\
\hline & Hubei & 34 & 0.049 & 35 & 0.051 & 6 & 0.022 & 75 & 0.045 \\
\hline & Hunan & 31 & 0.045 & 31 & 0.045 & 9 & 0.033 & 71 & 0.043 \\
\hline \multicolumn{2}{|l|}{ Total } & 173 & 0.250 & 168 & 0.245 & 43 & 0.158 & 384 & 0.233 \\
\hline \multirow{3}{*}{ Northeast } & Heilongjiang & 32 & 0.046 & 32 & 0.047 & 10 & 0.037 & 74 & 0.045 \\
\hline & Jilin & 24 & 0.035 & 24 & 0.035 & 5 & 0.018 & 53 & 0.032 \\
\hline & Liaoning & 31 & 0.045 & 31 & 0.045 & 11 & 0.040 & 73 & 0.044 \\
\hline \multicolumn{2}{|l|}{ Total } & 87 & 0.126 & 87 & 0.127 & 26 & 0.095 & 200 & 0.121 \\
\hline \multirow{12}{*}{ West } & Neimenggu & 20 & 0.029 & 20 & 0.029 & 6 & 0.022 & 46 & 0.028 \\
\hline & Guangxi & 23 & 0.033 & 23 & 0.034 & 8 & 0.029 & 54 & 0.033 \\
\hline & Chongqing & 1 & 0.001 & 1 & 0.001 & 5 & 0.018 & 7 & 0.004 \\
\hline & Sichuan & 35 & 0.050 & 35 & 0.051 & 10 & 0.037 & 80 & 0.048 \\
\hline & Guizhou & 13 & 0.019 & 13 & 0.019 & 2 & 0.007 & 28 & 0.017 \\
\hline & Yunnan & 20 & 0.029 & 17 & 0.025 & 7 & 0.026 & 44 & 0.027 \\
\hline & Xizang & 8 & 0.012 & 8 & 0.012 & 3 & 0.011 & 19 & 0.012 \\
\hline & Shanxi & 14 & 0.020 & 14 & 0.020 & 8 & 0.029 & 36 & 0.022 \\
\hline & Gansu & 17 & 0.024 & 17 & 0.025 & 8 & 0.029 & 42 & 0.025 \\
\hline & Qinghai & 12 & 0.017 & 12 & 0.018 & 3 & 0.011 & 27 & 0.016 \\
\hline & Ningxia & 8 & 0.012 & 8 & 0.012 & 8 & 0.029 & 24 & 0.015 \\
\hline & Xinjiang & 40 & 0.058 & 40 & 0.058 & 7 & 0.026 & 87 & 0.053 \\
\hline \multicolumn{2}{|l|}{ Total } & 211 & 0.304 & 208 & 0.304 & 75 & 0.274 & 494 & 0.300 \\
\hline \multicolumn{2}{|c|}{ Center } & 1 & 0.001 & 1 & 0.001 & 24 & 0.088 & 26 & 0.016 \\
\hline \multicolumn{2}{|l|}{ Sum } & 694 & 1.000 & 685 & 1.000 & 272 & 1.000 & 1651 & 1.000 \\
\hline
\end{tabular}

Table 9 indicates that the FSSIT of FDA and CA gradually declines when that at the administrative level decreases. The FSSIT scores of different administrative levels show that the food safety supervision works at the provincial level are more standardized than those at the prefectural and county levels. The local supervision works on food safety information transparency present deficiencies. Among them, the work at the county level is the worst. In such a case, the public's panic psychology and "herd instinct" easily occur in case of food safety accident. By contrast, the work at the central level is the most standardized and obtains the highest score.
Table 10 shows that, in the seven geographical regions in China, Eastern and Southern China obtain the highest score and at the general level. North, Northeast, Southwest, Northwest, and Central China obtain a lower score but at a qualified level. However, analyzing Tables 8 and 9 shows that the FSSIT of different geographical regions is mostly at a poor level; this poor performance is due to the poor level of CA at the county level. Comparing the entirety and central level with the seven geographical regions shows that the FSSIT at the central level presents the highest score and achieves a better level. The low scores of each geographical 
TABLE 7: Index weight.

\begin{tabular}{|c|c|c|c|c|c|}
\hline First-level index & Weight & Second-level index & Weight & Third-level index & Weight \\
\hline \multirow{13}{*}{$\mathrm{B}_{1}$} & \multirow{13}{*}{0.328} & \multirow{13}{*}{$\mathrm{C}_{1}$} & \multirow{13}{*}{0.250} & $\mathrm{C}_{11}$ & 0.097 \\
\hline & & & & $\mathrm{C}_{12}$ & 0.081 \\
\hline & & & & $\mathrm{C}_{13}$ & 0.078 \\
\hline & & & & $\mathrm{C}_{14}$ & 0.097 \\
\hline & & & & $\mathrm{C}_{15}$ & 0.091 \\
\hline & & & & $\mathrm{C}_{16}$ & 0.078 \\
\hline & & & & $\mathrm{C}_{17}$ & 0.065 \\
\hline & & & & $\mathrm{C}_{18}$ & 0.075 \\
\hline & & & & $\mathrm{C}_{19}$ & 0.037 \\
\hline & & & & $\mathrm{C}_{110}$ & 0.081 \\
\hline & & & & $\mathrm{C}_{111}$ & 0.075 \\
\hline & & & & $\mathrm{C}_{112}$ & 0.065 \\
\hline & & & & $\mathrm{C}_{113}$ & 0.081 \\
\hline \multirow{6}{*}{$\mathrm{B}_{1}$} & \multirow{6}{*}{0.328} & \multirow{6}{*}{$\mathrm{C}_{2}$} & \multirow{6}{*}{0.250} & $\mathrm{C}_{21}$ & 0.220 \\
\hline & & & & $\mathrm{C}_{22}$ & 0.110 \\
\hline & & & & $\mathrm{C}_{23}$ & 0.127 \\
\hline & & & & $\mathrm{C}_{24}$ & 0.127 \\
\hline & & & & $\mathrm{C}_{25}$ & 0.212 \\
\hline & & & & $\mathrm{C}_{26}$ & 0.203 \\
\hline \multirow{3}{*}{$\mathrm{B}_{1}$} & \multirow{3}{*}{0.328} & \multirow{3}{*}{$\mathrm{C}_{3}$} & \multirow{3}{*}{0.250} & $\mathrm{C}_{31}$ & 0.250 \\
\hline & & & & $\mathrm{C}_{32}$ & 0.250 \\
\hline & & & & $\mathrm{C}_{33}$ & 0.500 \\
\hline \multirow{5}{*}{$\mathrm{B}_{1}$} & \multirow{5}{*}{0.328} & \multirow{5}{*}{$\mathrm{C}_{4}$} & \multirow{5}{*}{0.250} & $\mathrm{C}_{41}$ & 0.147 \\
\hline & & & & $\mathrm{C}_{42}$ & 0.197 \\
\hline & & & & $\mathrm{C}_{43}$ & 0.255 \\
\hline & & & & $\mathrm{C}_{44}$ & 0.255 \\
\hline & & & & $\mathrm{C}_{45}$ & 0.147 \\
\hline \multirow{3}{*}{$\mathrm{B}_{2}$} & \multirow{3}{*}{0.260} & \multirow{3}{*}{$\mathrm{C}_{5}$} & \multirow{3}{*}{0.333} & $\mathrm{C}_{51}$ & 0.500 \\
\hline & & & & $\mathrm{C}_{52}$ & 0.250 \\
\hline & & & & $\mathrm{C}_{53}$ & 0.250 \\
\hline \multirow{3}{*}{$\mathrm{B}_{2}$} & \multirow{3}{*}{0.260} & \multirow{3}{*}{$\mathrm{C}_{6}$} & \multirow{3}{*}{0.333} & $\mathrm{C}_{61}$ & 0.260 \\
\hline & & & & $C_{62}$ & 0.328 \\
\hline & & & & $\mathrm{C}_{63}$ & 0.413 \\
\hline & & & & $\mathrm{C}_{71}$ & 0.286 \\
\hline & & & & $\mathrm{C}_{72}$ & 0.286 \\
\hline $\mathrm{B}_{2}$ & 0.260 & $\mathrm{C}_{7}$ & 0.333 & $\mathrm{C}_{73}$ & 0.143 \\
\hline & & & & $\mathrm{C}_{74}$ & 0.143 \\
\hline & & & & $\mathrm{C}_{75}$ & 0.143 \\
\hline & & & & $\mathrm{C}_{81}$ & 0.143 \\
\hline $\mathrm{B}_{3}$ & 0.413 & $\mathrm{C}_{8}$ & 0.500 & $\mathrm{C}_{82}$ & 0.286 \\
\hline & & & & $\mathrm{C}_{83}$ & 0.286 \\
\hline & & & & $\mathrm{C}_{84}$ & 0.286 \\
\hline $\mathrm{B}_{3}$ & 0.413 & $\mathrm{C}_{9}$ & 0.500 & $\mathrm{C}_{91}$ & 0.333 \\
\hline$z_{3}$ & & & & $\mathrm{C}_{92}$ & 0.667 \\
\hline
\end{tabular}

TABLE 8: Scores of various types of food safety supervision subjects.

\begin{tabular}{lccccccc}
\hline Evaluation goal & Score & Grade & Rank & Evaluation goal & Score & Grade & Rank \\
\hline Media & 66.675 & General & 1 & Entirety & 56.963 & Relatively poor & 3 \\
FDA & 57.455 & Relatively poor & 2 & CA & 40.895 & Relatively poor & 4 \\
\hline
\end{tabular}


TABLE 9: Scores of different administrative levels (media includes media bodies at the prefectural and county levels, but they show no specific distinction to those at the central and provincial levels; therefore, this study does not evaluate the FSSIT of media at different administrative levels.).

\begin{tabular}{|c|c|c|c|c|c|c|}
\hline Evaluation goal & Score of FDA & Grade & Rank & Score of CA & Grade & Rank \\
\hline Center & 95.416 & Good & 1 & 80.053 & Relatively good & 1 \\
\hline Province & 83.130 & Relatively good & 2 & 67.563 & General & 2 \\
\hline Prefecture & 70.638 & General & 3 & 46.605 & Relatively poor & 3 \\
\hline County & 41.588 & Relatively poor & 4 & 32.398 & Relatively poor & 4 \\
\hline
\end{tabular}

TABLE 10: Scores of different geographical regions.

\begin{tabular}{|c|c|c|c|c|c|c|}
\hline Geographical area & Score & Grade & Rank & Score of FDA & Score of CA & Score of media \\
\hline Center & 82.770 & Relatively good & 1 & 95.415 & 80.053 & 75.005 \\
\hline East China & 60.648 & General & 2 & 58.768 & 43.011 & 73.251 \\
\hline South China & 60.113 & General & 3 & 67.365 & 56.978 & 56.333 \\
\hline Entirety & 56.963 & Relatively poor & 4 & 57.455 & 40.895 & 66.675 \\
\hline North China & 55.135 & Relatively poor & 5 & 51.219 & 36.828 & 69.776 \\
\hline Northeast China & 55.016 & Relatively poor & 6 & 51.098 & 38.586 & 68.474 \\
\hline Southwest China & 54.250 & Relatively poor & 7 & 51.874 & 29.937 & 71.451 \\
\hline Northwest China & 52.815 & Relatively poor & 8 & 60.088 & 38.032 & 56.355 \\
\hline Central China & 52.315 & Relatively poor & 9 & 59.503 & 40.659 & 53.952 \\
\hline
\end{tabular}

TABLE 11: Scores of different economic regions.

\begin{tabular}{|c|c|c|c|c|c|c|}
\hline Economic region & Score & Grade & Rank & Score of FDA & Score of CA & Score of media \\
\hline Center & 82.770 & Relatively good & 1 & 95.415 & 80.053 & 75.005 \\
\hline East & 59.303 & Relatively poor & 2 & 61.314 & 45.632 & 66.318 \\
\hline Entirety & 56.963 & Relatively poor & 3 & 57.455 & 40.895 & 66.675 \\
\hline Central & 56.952 & Relatively poor & 4 & 55.646 & 42.377 & 67.169 \\
\hline Northwest & 55.016 & Relatively poor & 5 & 51.098 & 38.586 & 68.474 \\
\hline West & 54.242 & Relatively poor & 6 & 57.327 & 35.462 & 63.624 \\
\hline
\end{tabular}

region affect the entire FSSIT, thereby resulting in a relatively poor but qualified level. This situation reflects that the current overall situation of food safety supervision information is still insufficiently transparent and that the public's access right to food safety information needs to be further improved.

Table 11 shows that, in China's four economic regions, the FSSIT score of the eastern region is the highest, followed by that of the central, northeast, and western regions at a relatively poor level. Although the FSSIT of the four economic regions reach the qualified level, the transparency is still pessimistic. This finding is consistent with the results shown in Table 10. Comparing the entirety and central level with the four economic regions, only the FSSIT at the central level reaches a relatively good level and is affected by the low score of the four economic regions. The entire FSSIT is at a relatively poor level. These findings are consistent with the results shown in Table 10.

In summary, China has exerted much effort to improve FSSIT but presents a certain degree of work loss in the entirety, various types of food safety supervision subjects, and different administrative levels and regions. In addition, the public's access right to food safety information must be further enhanced.

\section{Discussion}

This study finds that the entire FSSIT work in China presents deficiencies, and those at the county level are serious. Local food safety supervision subjects expand supervision works according to the actual situation of each administrative region, and the released information meets the needs of the local public. However, the survey results show that FSSIT gradually declines when that at the administrative level decreases; this finding is consistent with the conclusions of the study of the Center for Public Participation Studies and Supports [17]. The FSSIT score of FDA, especially the low score at the prefectural and county levels, shows that the works of local FDA still present deficiencies despite the implementation of the 105th, 109th, 113th, 116th, 118th, and 119th "food safety law." Therefore, China's FDA reform exhibits a certain degree of deviation, and the reform fails to construct a unified and authoritative FDA and weakens the power of FDA in a few regions. At the end of 2014, 95\% of prefectural and $80 \%$ of county level works are independently set up by FDA. By the end of 2015, they reduced to $82 \%$ and $42 \%$, respectively; the numbers are still decreasing (source: the latest speech of $\mathrm{Bi}$ Jingquan at the CFDA National 
Bureau Chief on the consistency evaluation of generic drugs (http://www.cpia.org.cn/news/dt4381833320773.html)). In such a situation, China should perform adjustments to avoid deviating from the original intention of the reform.

From the FSSIT ranking of the different regions, the economic development level indirectly determines the FSSIT level. In general, highly developed economies perfectly conduct the corresponding work, including FSSIT. However, the entire FSSIT score of the different regions does not support this deduction. The detailed analysis shows that China has become the second largest economy in the world and has reached the level of a well-off society. The social construction of the country has also significantly improved. Therefore, the FSSIT in China should be at a good level. However, this study finds a different result. The FSSIT ranking of the different geographical regions meets the economic development ranking. However, the FSSIT level in Eastern and Northern China disagrees with the economic development level. Similarly, the FSSIT of the different economic regions also differs.

The FSSIT score shows that the entire FSSIT is qualified at present but is still in a relatively poor level; this situation is not conducive to ease rumors of "herd instinct" and does not promote healthy development of the food industry. In addition, food safety is ranked first in China's top 10 focus issues for four consecutive years; this phenomenon reflects the current lack of information transparency of food safety. If FDA, CA, and media can timely, accurately, and conveniently release food safety supervision information, then the public's panic can be reduced, the public's awareness of food safety incidents can be enhanced, and the rumors of "herd instinct" can be alleviated. However, as parts of food safety social supervision, CA and media fail to effectively spread food safety supervision information to the public, and FDA imperfectly conducts its works. This situation explains the public's amplification of current food safety issues in China and the public's certain degree of food safety fear and public's distrust of food companies. Among these issues, the most representative is the melamine incident, which triggered a distrust of domestic dairy of the entire society such that a huge loss of domestic dairy industry occurred $[47,48]$.

This study also indicates that the frequent food safety issues in China are due to the information asymmetry of food safety, which easily leads to adverse selection and moral hazard of food companies [48]. Food safety supervision mainly depends on food safety supervision department of government [13]. In working toward local economic development, local government may come into conflict with food companies $[49,50]$. This situation leads to the nontransparency of local food safety supervision information and difficulty in addressing food safety issues. CA and media cannot fully play their supervising roles when under pressure [50], thereby resulting in the lack of FSSIT work. In such a situation, the public's access to food safety supervision information becomes ineffective and the problem food companies cannot be eliminated using the power of the supervision subjects. The cost of compliant food companies is higher than that of the problem food companies; thus, the competitiveness of food companies declines or disappears $[12,26]$. In other words, the problem food companies willingly take risk of producing or selling problem food, while the compliant food companies cannot compete with the problem food companies because of cost and profit pressures. Accordingly, the products or sales of compliant food companies can disappear. If compliant food companies shift to producing or selling problem food, then the food safety situation in the entire society can deteriorate. This situation reflects that the difficulty in addressing China's food safety problem is indeed attributed mainly to the information asymmetry of food safety. Specifically, the public cannot effectively distinguish the problem food companies from the compliant food companies. This situation is conducive to adverse selection and moral hazard of the food companies.

\section{Conclusion}

On the basis of China's "food safety law" and existing literature, an index system of FSSIT is constructed in this study using the fuzzy-ANP comprehensive evaluation model and 1651 questionnaires. Using this system, the entirety, various types of food safety supervision subjects and different administrative levels and regions of FSSIT in China are evaluated. The empirical results are as follows:

(1) China has exerted much effort to improve FSSIT, and the entire FSSIT reaches a qualified level. However, FDA, CA, and media still imperfectly conduct their works, and supervision information asymmetry of food safety occurs. This situation is conducive to adverse selection and moral risk of food companies and cannot ease the rumor of "herd instinct" and promote healthy development of the food industry.

(2) FSSIT gradually declines when that in the administrative level decreases. The work of the local FSSIT presents deficiencies, and those at the county level are serious. This situation also reflects that China's FDA reform exhibits a certain degree of deviation, and the public's access right to food safety information needs to be further improved.

(3) The economic development level indirectly determines the FSSIT level. The current levels of FSSIT and economic development in the country do not match. This problem can be solved by cooperation among the food safety supervision subjects at different administrative levels and regions.

The results of this study not only help enhance the public's awareness on China's FSSIT but also provide a strong reference for the food safety supervision subjects to determine their own shortcomings and improve their work. However, only the data of FDA, CA, and media collected on 2016 are used, and no dynamic comparison is conducted. Therefore, future works can conduct the following tasks: track the original goals; research the continuous changes of FDA, CA, and media; promote various types of food safety supervision subjects to improve their work; and enhance the public's access right to food safety information. 


\section{Competing Interests}

The authors declare that they have no competing interests.

\section{Acknowledgments}

The authors wish to express their gratitude to Song Qinan. This work was supported by the Major Program of National Social Science Foundation of China (no. 12\&ZD204), the National Natural Science Foundation of China (no. 71173103 and no. 71501094), Jiangsu Natural Science Foundation (BK20150961), Natural Science Foundation project of the Jiangsu Higher Education Institutions (15KJB120003), and Jiangsu Higher Education Institutions sponsored by Qing Lan Project.

\section{References}

[1] J. Wang and Z. Pan, "Interest equilibrium evolution and research on food safety supervision from the perspective of social trust," Seeker in China, no. 9, pp. 1-4, 2011.

[2] J. Wang and T. Chen, "The spread model of food safety risk under the supply-demand disturbance," SpringerPlus, vol. 5, no. 1, 2016.

[3] J. E. Stiglitz, "The contributions of the economics of information to twentieth century economics," Quarterly Journal of Economics, vol. 115, no. 4, pp. 1441-1478, 2000.

[4] T. Vishwanath and D. Kaufmann, "Toward transparency: new approaches and their application to financial markets," World Bank Research Observer, vol. 16, no. 1, pp. 41-57, 2001.

[5] S. García Herrero, M. A. Mariscal Saldaña, M. A. Manzanedo del Campo, and D. O. Ritzel, "From the traditional concept of safety management to safety integrated with quality," Journal of Safety Research, vol. 33, no. 1, pp. 1-20, 2002.

[6] A. Das, M. Pagell, M. Behm, and A. Veltri, "Toward a theory of the linkages between safety and quality," Journal of Operations Management, vol. 26, no. 4, pp. 521-535, 2008.

[7] S. Quan and Y. Zeng, "Information concealing and conspiring problems of food safety regulators in China: interpretation based on principal-agent model and its practical verification," Management Review in China, vol. 28, no. 2, pp. 210-218, 2016.

[8] L. Heinzerling, "The varieties and limits of transparency in U.S. food law," Food and Drug Law Journal, vol. 70, no. 1, pp. 11-24, 2015.

[9] B. Klein and K. B. Leffler, "The role of market forces in assuring contractual performance," Journal of Political Economy, vol. 89, no. 4, pp. 615-641, 1981.

[10] C. Shapiro, "Premiums for high quality products as returns to reputations," The Quarterly Journal of Economics, vol. 98, no. 4, pp. 659-679, 1983.

[11] F. Allen, "Reputation and product quality," Rand Journal of Economics, vol. 15, no. 3, pp. 311-327, 1984.

[12] Q. Gong, Y. Zhang, and J. Yu, "Incentive, information and food safety regulation," Economic Research Journal in China, no. 3, pp. 135-147, 2013.

[13] A. P. J. Mol, "Governing China's food quality through transparency: a review," Food Control, vol. 43, no. 6, pp. 49-56, 2014.

[14] M. Garcia Martinez, A. Fearne, J. A. Caswell, and S. Henson, "Co-regulation as a possible model for food safety governance: opportunities for public-private partnerships," Food Policy, vol. 32, no. 3, pp. 299-314, 2007.
[15] Y. Chen, "An analysis of operating mechanism of food safety synergistic governance," Commercial Research in China, no. 1, pp. 60-65, 2014.

[16] J. Wang, T. Chen, and J. Wang, "Research on cooperation strategy of enterprises' quality and safety in food supply chain," Discrete Dynamics in Nature and Society, vol. 2015, Article ID 301245, 15 pages, 2015.

[17] Y. Wang, "Transparency of food safety supervision report released[EB/OL]," 2016 http://news.gmw.cn/2016-03/17/conent_19318549.htm.

[18] H. Yan and Y. Nie, "The logic of institution choice-the evolvement of China food security regulation system," Journal of Public Management in China, vol. 6, no. 3, pp. 12-25, 2009.

[19] S. Henson and J. Caswell, "Food safety regulation: an overview of contemporary issues," Food Policy, vol. 24, no. 6, pp. 589-603, 1999.

[20] J. M. Crespi and S. Marette, "How should food safety certification be financed?" American Journal of Agricultural Economics, vol. 83, no. 4, pp. 852-861, 2001.

[21] H. Lapan and G. Moschini, "Grading, minimum quality standards, and the labeling of genetically modified products," American Journal of Agricultural Economics, vol. 89, no. 12553, pp. 1222-1229, 2007.

[22] S. Marette, "Minimum safety standard, consumers' information and competition," Journal of Regulatory Economics, vol. 32, no. 3, pp. 259-285, 2007.

[23] P. Ferrier and R. Lamb, "Government regulation and quality in the US beef market," Food Policy, vol. 32, no. 1, pp. 84-97, 2007.

[24] J. J. Laffont and J. Tirole, "The politics of government decisionmaking: a theory of regulatory capture," Quarterly Journal of Economics, vol. 106, no. 4, pp. 1089-1127, 1991.

[25] M. Gorton, M. Dumitrashko, and J. White, "Overcoming supply chain failure in the agri-food sector: a case study from Moldova," Food Policy, vol. 31, no. 1, pp. 90-103, 2006.

[26] H. Wang, J. Xiao, K. Xie et al., "Food safety governance-a study combing information technology and institutional arrangement," China Industrial Economics, no. 3, pp. 98-110, 2013.

[27] X. Li and L. Shi, "An economics explanation for the crisis of trust in food industry," Economic Research Journal in China, no. 1, pp. 169-181, 2014.

[28] A. Florini, The Right to Know: Transparency for an Open World, Columbia University Press, 2007.

[29] L. S. Bennear and S. M. Olmstead, "The impacts of the "right to know": information disclosure and the violation of drinking water standards," Journal of Environmental Economics and Management, vol. 56, no. 2, pp. 117-130, 2008.

[30] C. Li and B. Jiang, "Trust evaluation of dairy products quality safety from the perspective of context and quality: based on the survey data of 12 provinces consumer dairy consumption," Issues in Agricultural Economy in China, no. 3, pp. 75-82, 2015.

[31] H. Wang, "Public participation in food safety management of the rule of law," Commercial Research in China, no. 4, pp. 170$177,2012$.

[32] X. Zhao, "Research on the government compulsory function of food safety information provision and its realizing path," Chinese Public Administration, no. 7, pp. 38-42, 2011.

[33] X. Wen and S. Wen, "The construction and improvement of food safety credit files," Management World in China, no. 7, pp. 174-175, 2012.

[34] L. Pan and X. Xu, "The Publicity of government information on food safety supervision," Chinese Public Administration, no. 4, pp. 29-31, 2013. 
[35] Y. Zhou and E. Wang, "Chinese food safety regulation: a general framework," Reform in China, no. 4, pp. 19-28, 2013.

[36] J. Xu, "Scientific grasp of several relations in the revision of the food safety law," The Jurist in China, no. 6, pp. 47-51, 2013.

[37] W. Zeng and J. Lin, "The implementation of international soft law on food safety supervision in China," China Soft Science, vol. 5, pp. 12-20, 2015.

[38] M. Li and S. Dong, "Discuss on China's food safety social supervision," Dongyue Tribune in China, vol. 34, no. 11, pp. 179182, 2013.

[39] Q. Gong, L. Lei, and Y. Yuan, "Policy burden, regulatory capture and food safety," Economic Research Journal in China, no. 8, pp. 4-15, 2015.

[40] T. Yasuda, "Food safety regulation in the United States: an empirical and theoretical examination," Independent Review, vol. 15, no. 2, pp. 201-226, 2010.

[41] M. G. Martinez, P. Verbruggen, and A. Fearne, "Risk-based approaches to food safety regulation: What role for coregulation?" Journal of Risk Research, vol. 16, no. 9, pp. 1101-1121, 2013.

[42] W. Guo and S. Sun, "Coordination mechanism study of supervision on 'multi-links with alterable participants' behavior-take the food safety case as an example," Industrial Engineering and Management in China, vol. 18, no. 6, pp. 139-146, 2013.

[43] X. Yin and M. Liu, "To speed up the food safety supervision system, capacity and environment build," Consumer Economics in China, no. 2, pp. 17-19, 2012.

[44] Q. Li, "A effective way to improve the performance of food safety governance based on cooperative game," in Proceedings of the International Conference on Agricultural Risk and Food Security (ARFS '10), pp. 423-428, Harbin, China, June 2010.

[45] T. L. Saaty, Decision Making with Dependence and Feedback: The Analytic Network Process, RWS Publications, Pittsburgh, Pa, USA, 1996.

[46] A. Sala, T. M. Guerra, and R. Babuška, "Perspectives of fuzzy systems and control," Fuzzy Sets and Systems, vol. 156, no. 3, pp. 432-444, 2005.

[47] C. Wang and H. Gu, "Are consumers having a poor memory?-An economics analysis on the tolerance of consumer about the company having problem of food safety in China," Research on Economics and Management in China, no. 10, pp. 121-128, 2012.

[48] S. Tao and Y. Zhou, "Study on trust mechanism of food safety," Issues in Agricultural Economy in China, no. 10, pp. 93-99, 2012.

[49] F. Yang, "Difficulties and countermeasure in the governance of food safety based on interest game," Commercial Research in China, no. 5, pp. 194-199, 2012.

[50] W. Yuan and K. Hu, "Inter-governmental Game Model and Policy Implication of Food Safety Regulation, the game model and policy implications of the government in food safety regulation," Chinese Public Administration, no. 7, pp. 101-105, 2014. 

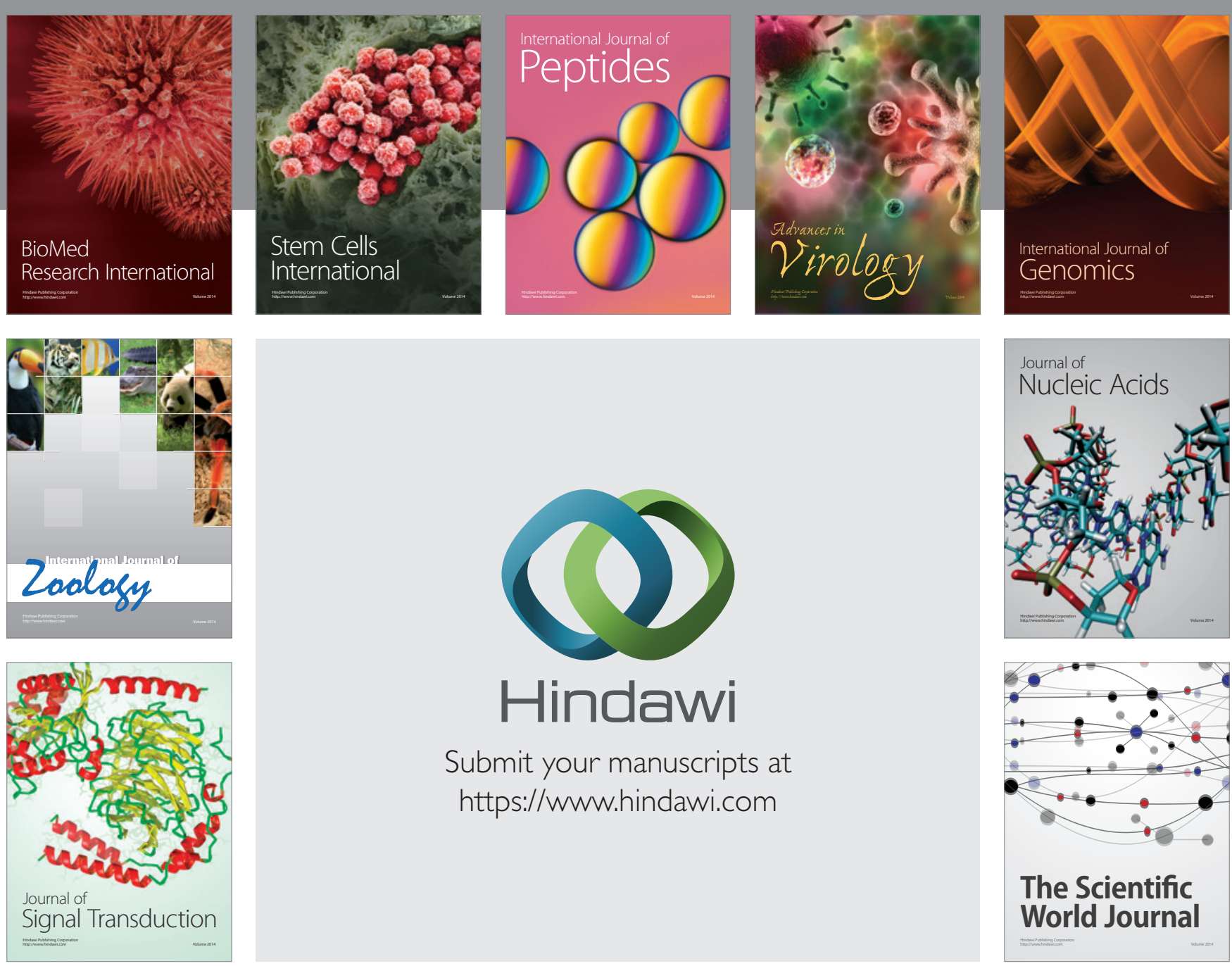

Submit your manuscripts at

https://www.hindawi.com
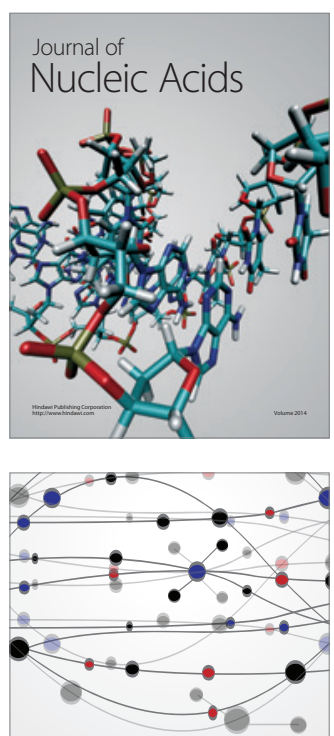

The Scientific World Journal
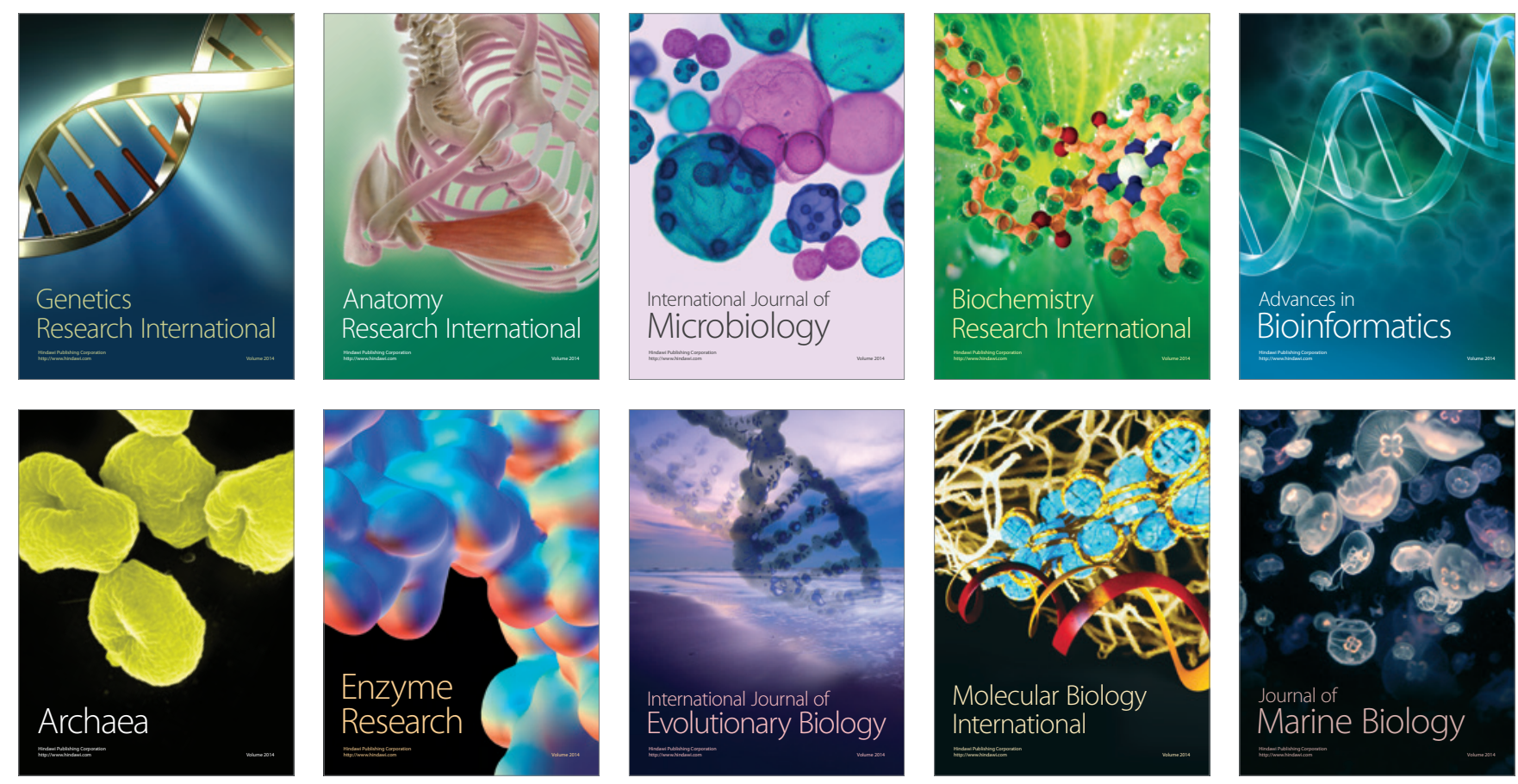